\title{
STUDI SISTEM DRAINASE JALAN GARUDA XA KECAMATAN JEKAN RAYA KOTA PALANGKA RAYA
}

\author{
Novrianti \\ Program Studi Teknik Lingkungan UM Palangka Raya
}

\begin{abstract}
ABSTRAK
Kondisi Kota Palangka Raya yang semakin banyak penduduk sehingga terjadi peningkatan terhadap jumlah perumahan, pertokoan, perindustrian, maupun perhotelan. Hal ini menyebabkan terjadi pengurangan yang signifikan terhadap resapan air ke dalam tanah. Pengaliran air di atas permukaan tanah tidak dapat mengalir dengan baik akibat kurangnya resapan tersebut. Drainase sangat diperlukan dalam mengalirkan aliran air permukaan yang sebagian di resapkan di dalam tanah dan diharapkan sebagian lagi dialirkan ketempat pengaliran saluran primer maupun sungai. Dengan perencanaan drainase yang kurang baik tanpa memikirkan kemana aliran yang harusnya di alirkan maka menyebabkan salah satu penyebab banjir, hal lain penyebab banjir adalah kondisi existing drainase yang tidak terpelihara juga dapat menyebabkan banjir.

Penelitian ini mempunyai tujuan untuk mengetahui kondisi sistem dan saluran drainase yang telah ada serta mengetahui perbandingan antara debit rasional (Qr) dan debit saluran (Qs) pada wilayah penelitian.

Berdasarkan hasil data lapangan saluran eksisting, lebar dasar saluran (b) bervariasi antara 0,25 m - 0,50 $\mathrm{m}$, dan kedalaman saluran bervariasi antara $0,35 \mathrm{~m}-0,70 \mathrm{~m}$. Dari hasil perhitungan daerah kawasan garuda XA menunjukkan perbandingan bahwa Qr < Qs per periode 2, 5, 10, 25 sehingga dikatakan tidak banjir dan sudah cukup untuk kapasitas dimensi saluran. Kondisi banjir yang terjadi pada waktu tahun 2015 adalah keadaan genangan sesaat dikarenakan pada lokasi tertentu dibeberapa tempat tidak mempunyai saluran dan kurang terawatnya drainase yang ada.
\end{abstract}

\section{Kata kunci: Studi Sistem Drainase, Jekan Raya, Saluran Drainase}




\section{PENDAHULUAN}

Kondisi Kota Palangka Raya yang semakin banyak penduduk sehingga terjadi peningkatan terhadap jumlah perumahan, pertokoan, perindustrian, maupun perhotelan. Hal ini menyebabkan terjadi pengurangan yang signifikan terhadap resapan air ke dalam tanah.

Pengaliran air di atas permukaan tanah tidak dapat mengalir dengan baik akibat kurangnya resapan tersebut. Drainase sangat diperlukan dalam mengalirkan aliran air permukaan yang sebagian di resapkan di dalam tanah dan diharapkan sebagian lagi dialirkan ketempat pengaliran saluran primer maupun sungai.

Dengan perencanaan drainase yang kurang baik tanpa memikirkan kemana aliran yang harusnya di alirkan maka menyebabkan salah satu penyebab banjir, hal lain penyebab banjir adalah kondisi existing drainase yang tidak terpelihara juga dapat menyebabkan banjir.

\section{Tujuan Penelitian}

Adapun tujuan dari penelitian ini adalah:

1. Bagaimana sistem drainase yang telah ada?

2. Bagaimana kondisi saluran drainase yang telah ada?

3. Bagaimana perbandingan antara Debit Rasional (Qr) dan Debit Saluran (Qs) yang terjadi?

\section{Batasan Masalah}

Lokasi penelitian dilakukan pada kawasan Jalan Garuda XA dan sekitarnya

\section{Tujuan Penelitian}

Tujuan dari penelitian ini adalah:

1. Mengetahui debit air berdasarkan curah hujan Kota Palangka Raya

2. Mengetahui dimensi saluran pada masingmasing ruas saluran drainase yang ada di lapangan.

3. Mengetahui perbandingan antara Debit Rasional (Qr) dan Debit Saluran (Qs) yang terjadi.

\section{Manfaat Penelitian}

Manfaat dari penelitian ini adalah memberikan informasi apakah Debit Rasional (Qr) > Debit Saluran (Qs) atau sebaliknya.

\section{TINJAUAN PUSTAKA}

Drainase merupakan salah satu fasilitas dasar yang dirancang sebagai sistem guna memenuhi kebutuhan masyarakat dan merupakan komponen penting dalam perencanaan kota (perencanaan infrastruktur khususnya). Menurut Suripin (2004) drainase mempunyai arti mengalirkan, menguras, membuang atau mengalihkan air. Secara umum drainase didefinisikan sebagai serangkaian bangunan air yang berfungsi untuk mengurangi dan atau membuang kelebihan air dari suatu kawasan atau lahan, sehingga lahan dapat difungsikan secara optimal. Sistem jaringan drainase perkotaan umumnya dibagi atas 2 bagian, yaitu sistem drainase makro dan sistem drainase mikro, sedangkan saluran drainase dibedakan menjadi 3 bagian yaitu saluran drainase primer, saluran drainase sekunder dan saluran drainase tersier (Ayu dkk, 2013 dalam Novrianti, 2015).

Walaupun hubungan curah hujan dan limpasan tidak di definisikan dengan baik, limpasan biasanya naik sebanding dengan curah hujan pada dataran drainase (Sutanto, 2006).

\section{Pengukuran Langsung}

Pengukuran air banjir secara langsung terdiri dari pengukuran yang dilakukan sewaktu kejadian banjir. Debit (discharge) ditentukan serentak dengan mengukur kedalaman aliran dan kecepatan di sejumlah titik pada irisan melintang untuk menentukan perubahan yang menyolok pada kedalaman dan kecepatan arus. Dari pengukuran ini, luas dan kecepatan rata-rata dapat ditentukan dan debit dapat dihitung. Pengukuran debit pada berbagai tingkat pada lapangan atau pada stasiun pengukuran akan memberikan data untuk menjabarkan kurva skala (rating) atau penggambaran tingkat menurut debitnya. Rekaman yang terus menerus dari stasiun pengukuran tingkat memberikan data debit untuk mempelajari interval atau frekuensi banjir (Sutanto, 2006).

\section{Pengukuran Tidak Langsung}

Pengukuran tidak langsung dilakukan apabila tidak mungkin memberikan atau tidak praktis untuk mengukur aliran banjir secara langsung. Umumnya, pengukuran ini dilakukan setelah terjadinya banjir. Pengukuran tersebut termasuk 
marka tinggi air, geometri saluran, dan suatu perkiraan koefisien kekasaran. Dari data tersebut, besarnya banjir dihitung dengan menggunakan persamaan hidrolik dasar. Metode tidak langsung untuk menentukan besarnya banjir sebenarnya termasuk luas kemiringan, tanggul yang dapat dilewati aliran, bukaan yang menyempit dan bendungan pelimpas (Sutanto, 2006).

\section{Analisis Curah Hujan}

Jumlah hujan yang terjadi dalam suatu Daerah Aliran Sungai (DAS) merupakan besaran yang sangat penting dalam sistem DAS tersebut, karena hujan merupakan masukan utama ke dalam suatu DAS. Pengukuran hujan harus dilakukan dengan secermat mungkin. Untuk memperoleh data atau perkiraan besaran hujan yang baik terjadi dalam suatu DAS, diperlukan sejumlah stasiun hujan (Triatmodjo, 2010).

\section{Debit Rencana}

Debit rencana adalah debit maksimum yang akan dialirkan oleh saluran drainase untuk mencegah terjadinya genangan. Untuk drainase perkotaan dan jalan raya, sebagai debit rencana debit banjir maksimum periode ulang 5 tahun yang mempunyai makna kemungkinan banjir maksimum tersebut disamai atau dilampaui 1 kali dalam 5 tahun atau 2 kali dalam 10 tahun atau 20 kali dalam 100 tahun. Penetapan debit banjir maksimum periode ulang 5 tahun ini berdasarkan pertimbangan:

1. Resiko akibat genangan yang ditimbulkan oleh hujan relatif kecil dibandingkan dengan banjir yang ditimbulkan meluapnya sebuah sungai.

2. Luas lahan diperkotaan relatif terbatas, apabila ingin direncanakan saluran yang melayani debit banjir maksimum periode ulang lebih besar dari 5 tahun.

3. Daerah perkotaan mengalami perubahan dalam periode tertentu sehingga mengakibatkan perubahan pada saluran drainase.

Dalam perencanaan saluran drainase dapat dipakai standar yang telah ditetapkan, baik debit rencana (periode ulang) dan cara analisis yang dipakai, tinggi jagaan, struktur saluran dan lain-lain. Tabel 2.1 berikut menyajikan standar desain saluran drainase berdasar "Pedoman Drainase Perkotaan dan Standar Desain Teknis".
Tabel 2.1 Kriteria Desain Hidrologi Sistem Drainase Perkotaan

\begin{tabular}{|c|c|c|}
\hline $\begin{array}{c}\text { Luas DAS } \\
\text { (ha) }\end{array}$ & $\begin{array}{c}\text { Periode } \\
\text { Ulang } \\
\text { (tahun) }\end{array}$ & $\begin{array}{c}\text { Metode Perhitungan } \\
\text { Debit Banjir }\end{array}$ \\
\hline$<10$ & 2 & Rasional \\
\hline $10-100$ & $2-5$ & Rasional \\
\hline $101-$ & $5-20$ & Rasional \\
500 & & Hidrograf Satuan \\
\hline$>500$ & $10-25$ & \\
\hline
\end{tabular}

Sumber: Suripin (2004)

Dari Kriteria Desain Hidrologi Sistem Drainase Perkotaan maka digunakan Metode Rasional. Metode ini sangat simple dan mudah dalam penggunaannya, namun penggunaannya terbatas untuk DAS-DAS dengan ukuran kecil kurangd ari 300 ha. Model ini tidakd apat menerangkan hubungan curah hujan dan aliran permukaan dalam bentuk hidrograf. Persamaan metode rasional dapat ditulis dalam bentuk:

$$
\text { Qr }=0,278 \text { C I A }
$$

$$
\text { Keterangan: } \quad \begin{array}{ll}
\text { Qr } & =\text { Debit Rasional }\left(\mathrm{m}^{3} / \mathrm{dtk}\right) \\
\mathrm{C} & =\text { KoefisienPengaliran } \\
\mathrm{I} & =\text { IntensitasHujan }(\mathrm{mm} / \mathrm{jam}) \\
\mathrm{A} & =\text { Luas DAS }\left(\mathrm{km}^{2}\right)
\end{array}
$$

Langkah-langkah perhitungan debit rasional sebagai berikut:

1. Menghitung Koefisien Pengaliran $0 \leq \mathrm{C} \leq 1$

2. Menghitung Intensitas Hujan $\mathrm{I}=\frac{R 24}{24}\left(\frac{24}{t}\right)^{2 / 3}$ $\mathrm{t}=0,76 A^{0,38}$

\section{Perhitungan Debit Saluran}

Pada umumnya tipe aliran melalui saluran terbuka adalah turbulen, karena kecepatan aliran dan kekasaran dinding relative besar. Untuk mencari nilai kecepatan aliran dapat menggunakan rumus Manning yang dapat ditulis sebagai berikut: $V=\frac{1}{n} x R^{2 / 3} x S^{1 / 2}$

$$
\begin{array}{ll}
\text { Keterangan: } & R=\text { Jari-jari Hidraulik }(\mathrm{m}) \\
& S=\text { Kemiringan Dasar Saluran } \\
& n=\text { Koefisien Manning }
\end{array}
$$


Untuk mencari debit aliran pada saluran dapat menggunakan rumus:

$\mathrm{Qs}=\mathrm{V} \cdot \mathrm{A}$

Keterangan:

Qs = Debit aliranpadasaluran $\left(\mathrm{m}^{3} / \mathrm{dtk}\right)$

$\mathrm{V}=$ KecepatanAliran $(\mathrm{m} / \mathrm{dtk})$

$\mathrm{A}=$ Luas Penampang BasahSaluran $\left(\mathrm{m}^{2}\right)$

\section{METODE PENELITIAN}

\section{Lokasi Penelitian}

Lokasi penelitian dipusatkan di Jalan Yos Sudarso dan sekitarnya Kota Palangka Raya. Dasar dan pertimbangan yang dipergunakan adalah hasil dari survai lapangan.

\section{Tahapan Penelitian}

Secara umum penelitian dilakukan dalam dua tahap yaitu: Pengumpulan data dan analisis data. Jenis data yang dikumpulkan sebagai bahan analisis adalah data sekunder dan data primer. Data sekunder berupa hasil terdahulu yang terdiri dari peta dan data curah hujan. Disamping untuk dianalisis, sebagian data sekunder tersebut juga akan dijadikan pedoman dalam pengumpulan data primer. Data primer yang dikumpulkan antara lain profil memanjang dan melintang saluran dan kondisi sistem drainase.

\section{Teknik Pengumpulan Data}

\section{Data Sekunder}

a. Data Hujan

Data hujan yang diperlukan adalah data harian maksimum dalam satu tahun. Data curah hujan yang dimaksud adalah data yang tercatat pada stasiun hujan Palangka Raya. Periode pengamatan hujan tersebut diperoleh langsung dari Badan Meteorologi, Klimatologi dan Geofisika (BMKG) Propinsi Kalimantan Tengah.

b. Peta

Peta di dapat dari hasil lapangan.

\section{Data Primer}

Data primer yang dikumpulkan berupa profil melintang dan memanjang saluran drainase yang akan dikaji serta kondisi sistem drainase dengan cara melakukan pengukuran langsung ke lapangan. Alat yang digunakan adalah Waterpass/Total Station (TS) dan GPS.

\section{Analisis Data}

Analisis data menggunakan metode Rasional untuk menghitung debit hujan dan rumus Manning untuk menentukan debit saluran.

berikut:

Tahapan analisis data adalah sebagai

1. Perhitungan beban drainase (Qr)

Beban drainase dihitung dengan metode Rasional melalui langka-langkah perhitungan sebagai berikut:

a. Penentuan luas daerah aliran sungai/tangkapan hujan

Luas tangkapan hujan untuk masing-masing daerah ditentukan dengan memperhatikan faktor topografi atau dengan melihat arah dominan aliran.

b. Curah hujan rencana

Curah hujan rencana menggunakan Distribusi Probabilitas Gumbel, Normal, Log Normal dan Log Pearson Type III.

c. Pengujian distribusi probabilitas hujan rancangan

Curah hujan rancangan yang dihasilkan diuji kesesuaiannya dengan cara Smirnov Kolmogorov (Soewarno, 1995).

d. Perhitungan waktu konsentrasi/waktu respon banjir (tc).

e. Perhitungan Intensitas Curah Hujan (I) dengan cara Mononobe.

f. Perhitungan koefisien pengaliran tangkapan hujan (C).

g. Perhitungan beban drainase (Qr) dengan metode Rasional

2. Penentuan kapasitas drainase (Qs)

Perhitungan Qs menggunakan rumus aliran seragam Manning.

berikut :

Proses perhitungan dilakukan sebagai

a. Menghitung kemiringan saluran

b. Menghitung luas penampang saluran (A)

c. Menghitung keliling basah saluran $(\mathrm{P})$

d. Menghitung jari-jari hidraulik (R)

e. Menentukan nilai $\mathrm{n}$ daritabelkekasaran Manning

f. Menghitungkecepatanaliran (V)

g. Menghitung debit aliran (Qs)S 


\section{Perbandingan antara Debit Rasionaldan Debit Saluran}

Dari analisis data akan diperoleh perbandingan antara Debit Rasional (Qr) dan Debit Saluran (Qs), apabila Qr > Qs maka daerah penelitian merupakan daerah rawan banjir.

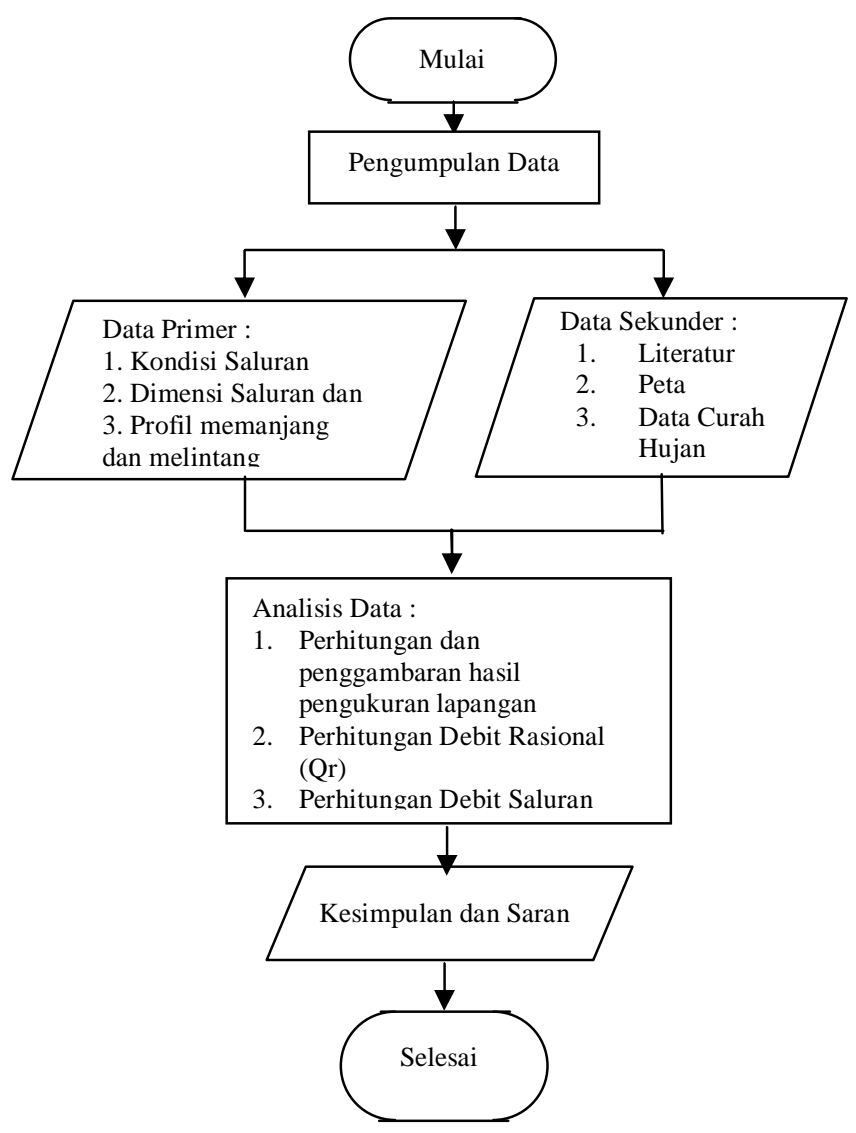

\section{PEMBAHASAN}

Penelitian ini dilakukan di daerah Jalan Garuda XA. Peta lokasi sebagai berikut:

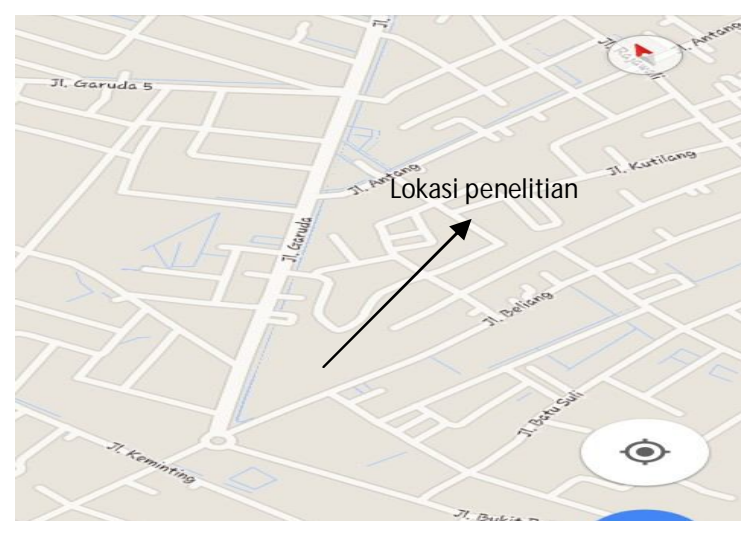

Gambar 1.1 Lokasi Penelitian

\section{Pengumpulan Data}

Data curah hujan yang digunakan untuk perhitungan curah hujan rencana adalah data curah hujan yang diperoleh dari pos hujan Palangka Raya. Data hujan tersebut merupakan data hujan harian maksimum, dengan periode pengamatan adalah 17 tahun yaitu dari tahun 1998 sampai tahun 2014. Selanjutnya data hujan tersebut dapat dilihat pada tabel di bawah ini:

Tabel 4.1 Data curah hujan maksimal Palangka Raya

\begin{tabular}{|c|c|c|}
\hline No. & Tahun & $\begin{array}{c}\text { Pos Hujan Palangka Raya } \\
(\mathrm{mm})\end{array}$ \\
\hline 1. & 1998 & 67,90 \\
\hline 2. & 1999 & 83,40 \\
\hline 3. & 2000 & 113,00 \\
\hline 4. & 2001 & 102,10 \\
\hline 5. & 2002 & 81,50 \\
\hline 6. & 2003 & 135,00 \\
\hline 7. & 2004 & 106,50 \\
\hline 8. & 2005 & 78,00 \\
\hline 9. & 2006 & 68,00 \\
\hline 10. & 2007 & 103,20 \\
\hline 11. & 2008 & 127,50 \\
\hline 12. & 2009 & 76,50 \\
\hline 13. & 2010 & 82,40 \\
\hline 14. & 2011 & 106,00 \\
\hline 15. & 2012 & 176,40 \\
\hline 16. & 2013 & 129,70 \\
\hline 17. & 2014 & 137,50 \\
\hline (Sumber: & $\begin{array}{c}\text { Badan Meteorologi, Klimatologi dan Geofisika } \\
\text { (BMKG) Propinsi Kalimantan Tengah) }\end{array}$ \\
\hline
\end{tabular}

\section{Kondisi Saluran dan Bangunan Silang}

Jaringan drainase yang ada pada kawasan Perumahan Jalan Garuda XA sebagian merupakan jaringan drainase pasangan batu dan sebagian lagi merupakan drainase tanah. sehingga kurang dapat mengalirkan debit air yang ada. Kondisi saluran yang kurang terawat seperti banyaknya endapan lumpur dan tanaman liar pada saluran mengakibatkan saluran tidak mampu menampung beban drainase yang ada.

\section{Metode Gumbel}

Dari curah hujan 16 tahun, untuk hujan rancangan metode distribusi Gumbel maka nilai Yn $=0,5157$ dan Sn 1,0316. Dengan hasil perhitungan di bawah ini: 
Tabel. 4.2 Hasil Hujan Rancangan Metode Distribusi Gumbel

\begin{tabular}{|c|c|c|c|c|c|}
\hline $\begin{array}{c}\mathrm{Tr} \\
(\text { Tahun })\end{array}$ & $\begin{array}{c}\mathrm{X}_{\mathrm{rt}} \\
(\mathrm{mm})\end{array}$ & $\mathrm{YT}$ & $\mathrm{K}$ & $\begin{array}{c}\mathrm{S} \\
(\mathrm{mm})\end{array}$ & $\begin{array}{c}\mathrm{X}_{\mathrm{TR}} \\
(\mathrm{mm})\end{array}$ \\
\hline 2 & 57.477 & 0.367 & -0.145 & 17.309 & 54.973 \\
\hline 5 & 57.477 & 1.500 & 0.954 & 17.309 & 73.991 \\
\hline 10 & 57.477 & 2.250 & 1.682 & 17.309 & 86.582 \\
\hline 25 & 57.477 & 3.199 & 2.601 & 17.309 & 102.491 \\
\hline
\end{tabular}

Sumber: hasil perhitungan

\section{Metode Normal} didapat:

Dalam perhitungan distribusi Normal

$$
\begin{aligned}
& \mathrm{Cv}=0,30 \\
& \mathrm{Cs}=1,27
\end{aligned}
$$

Dengan hasil perhitungan di bawah ini:

Tabel. 4.3 Hasil Hujan Rancangan Metode Distribusi Normal

\begin{tabular}{|c|c|c|c|c|}
\hline $\begin{array}{c}\text { Tr } \\
\text { (tahun) }\end{array}$ & Xrt (mm) & $\mathrm{K}$ & $\mathrm{S}$ & $\mathrm{Xtr}(\mathrm{mm})$ \\
\hline 2 & 57.48 & 0 & 17.309 & 57.477 \\
\hline 5 & 57.48 & 0.84 & 17.309 & 72.016 \\
\hline 10 & 57.48 & 1.28 & 17.309 & 79.632 \\
\hline 25 & 57.48 & 1.71 & 17.309 & 87.075 \\
\hline
\end{tabular}

Sumber: hasil perhitungan

\section{Metode Log Normal} didapat:

Dalam perhitungan distribusi Log Normal

$$
\mathrm{Cv}=0,07
$$$$
\mathrm{Cs}=0,36
$$

Dengan hasil perhitungan di bawah ini:

Tabel. 4.4 Hasil Hujan Rancangan Metode Distribusi Log Normal

\begin{tabular}{|c|c|c|c|c|}
\hline $\begin{array}{c}\text { Tr } \\
\text { (tahun) }\end{array}$ & Xrt (mm) & $\mathrm{K}$ & $\mathrm{S}$ & $\mathrm{Xtr}(\mathrm{mm})$ \\
\hline 2 & 1.74 & 0 & 0.12 & 1.743 \\
\hline 5 & 1.74 & 0.84 & 0.12 & 1.846 \\
\hline 10 & 1.74 & 1.28 & 0.12 & 1.900 \\
\hline 25 & 1.74 & 1.71 & 0.12 & 1.952 \\
\hline
\end{tabular}

Sumber: hasil perhitungan

\section{Metode Log Pearson Type III} didapat:

Dalam perhitungan distribusi Log Normal

$$
\mathrm{Cv}=0,07
$$$$
\mathrm{Cs}=0,36
$$

Dengan hasil perhitungan di bawah ini:

Tabel. 4.5 Hasil Hujan Rancangan Metode Distribusi Log Pearson Type III

\begin{tabular}{|c|c|c|c|c|c|}
\hline $\begin{array}{c}\text { Tr } \\
\text { (tahun) }\end{array}$ & $\begin{array}{c}\text { Log Xrt } \\
(\mathrm{mm})\end{array}$ & $\begin{array}{c}\mathrm{S} \\
(\mathrm{mm})\end{array}$ & $\mathrm{G}$ & $\begin{array}{c}\text { Xtr } \\
(\mathrm{mm})\end{array}$ & $\begin{array}{c}\text { Log10 Xtr } \\
(\mathrm{mm})\end{array}$ \\
\hline 2 & 1.74 & 0.12 & -0.0596 & 1.735 & 54.383 \\
\hline 5 & 1.74 & 0.12 & 0.8192 & 1.843 & 69.693 \\
\hline 10 & 1.74 & 0.12 & 1.3138 & 1.904 & 80.135 \\
\hline 25 & 1.74 & 0.12 & 1.8676 & 1.972 & 93.693 \\
\hline
\end{tabular}

Sumber: hasil perhitungan

Tabel. 4.6 Rekapitulasi Nilai Curah Hujan Rancangan

\begin{tabular}{|c|c|c|c|c|}
\hline \multirow{2}{*}{$\begin{array}{c}\text { Periode Ulang } \\
\text { Tr } \\
\text { (Tahun) }\end{array}$} & \multicolumn{4}{|c|}{ Curah Hujan Rencana XTR } \\
\cline { 2 - 5 } & Gumbel & Normal & $\begin{array}{c}\text { Log } \\
\text { Normal } \\
\mathbf{m m}\end{array}$ & $\begin{array}{c}\text { Log Pearson } \\
\text { Type III } \\
\mathbf{m m}\end{array}$ \\
\hline 2 & 54.973 & 57.477 & 55.305 & 54.383 \\
\hline 5 & 73.991 & 72.016 & 70.103 & 69.693 \\
\hline 10 & 86.582 & 79.632 & 79.374 & 80.135 \\
\hline 25 & 102.491 & 87.075 & 89.617 & 93.693 \\
\hline
\end{tabular}

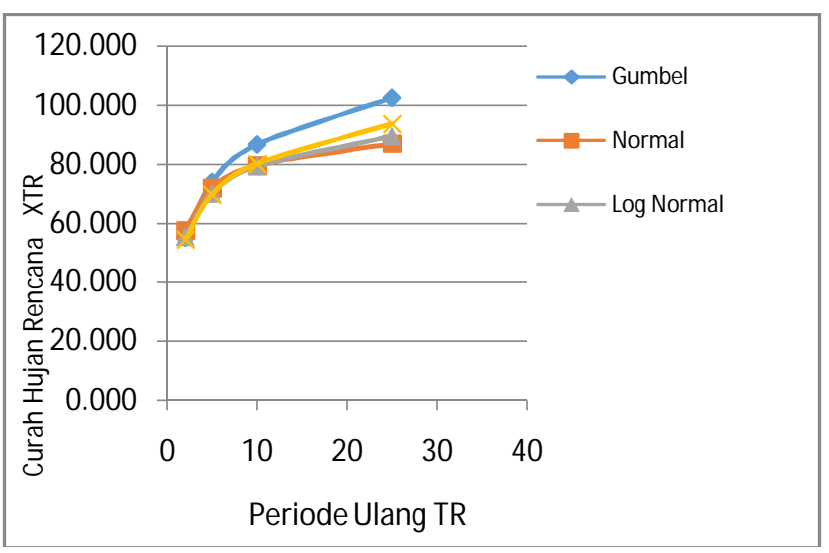

Gambar 4.1 Grafik Rekapitulasi Nilai Curah Hujan Rancangan

\section{Pengujian Uji Smirnov Kolmogorov}

Dari hasil perhitungan hujan rancangan metode Distribusi Log Pearson Type III di dapat hasil perhitungan di bawah ini: 
Tabel. 4.7 Hasil Perhitungan Pengujian Smirnov Kolmogorov

\begin{tabular}{|c|c|c|c|c|}
\hline$m$ & $P e(X)$ & $\begin{array}{c}X \\
(m m)\end{array}$ & $P t(X)$ & $P e(X)-P t(X)$ \\
\hline 1 & 2 & 3 & 4 & 5 \\
\hline 1 & 0.059 & 33.47 & 0.031 & 0.027 \\
\hline 2 & 0.118 & 35.11 & 0.088 & 0.030 \\
\hline 3 & 0.176 & 46.28 & 0.284 & -0.108 \\
\hline 4 & 0.235 & 48.10 & 0.336 & -0.101 \\
\hline 5 & 0.294 & 48.73 & 0.353 & -0.059 \\
\hline 6 & 0.353 & 48.79 & 0.355 & -0.002 \\
\hline 7 & 0.412 & 55.10 & 0.518 & -0.106 \\
\hline 8 & 0.471 & 54.67 & 0.507 & -0.036 \\
\hline 9 & 0.529 & 54.67 & 0.507 & 0.022 \\
\hline 10 & 0.588 & 56.89 & 0.560 & 0.028 \\
\hline 11 & 0.647 & 60.68 & 0.632 & 0.015 \\
\hline 12 & 0.706 & 61.34 & 0.646 & 0.060 \\
\hline 13 & 0.765 & 61.56 & 0.650 & 0.115 \\
\hline 14 & 0.824 & 62.38 & 0.666 & 0.158 \\
\hline 15 & 0.882 & 94.03 & 0.961 & -0.079 \\
\hline 16 & 0.941 & 97.83 & 0.977 & -0.035 \\
\hline
\end{tabular}

Sumber: hasil perhitungan

Dari perhitungan tersebut dengan $\alpha=5 \%$, di dapat nilai $\Delta \max =-0.071<$ Dkritis $=0.328$ (tabel nilai kritis smirnov kolmogorov), maka distribusi dapat diterima.

\section{Intensitas Hujan Rancangan}

Intensitas Hujan Rancangan (I) dengan periode ulang tertentu dengan digunakan metode Mononobe sehingga diperoleh:

Periode ulang 2 tahun untuk daerah $\mathrm{A}_{1}$ Jalan Garuda XA:

$$
\begin{aligned}
\mathrm{I} & =\frac{R 24}{24}\left(\frac{24}{t}\right)^{2 / 3} \\
& =\frac{1,735}{24}\left(\frac{24}{0,137}\right)^{2 / 3} \\
& =91,005 \mathrm{~mm} / \mathrm{jam}
\end{aligned}
$$

\section{Menghitung Debit Rasional}

Perhitungan debit rencana A1 dengan periode ulang 2 tahun $(\mathrm{Qr})$ :

$$
\begin{aligned}
\mathrm{Qr}_{2} & =0,00278 \mathrm{C} \mathrm{I} \text { A } \\
& =0,00278 \times 0,3315 \times 91,005 \times 0,01097 \\
& =0,0007178 \mathrm{~m}^{3} / \mathrm{dtk}
\end{aligned}
$$

Tabel. 4.8 Hasil perhitungan Debit Rasional

\begin{tabular}{|c|c|c|}
\hline No & $\begin{array}{c}\text { Periode Ulang } \\
\text { Tr } \\
\text { (Tahun) }\end{array}$ & $\begin{array}{c}\text { Debit Rasional } \\
\text { (Qr) }\end{array}$ \\
\hline 1. & 2 & 0,0423 \\
\hline 2. & 5 & 0,0543 \\
\hline 3. & 10 & 0,0624 \\
\hline 4. & 25 & 0,0730 \\
\hline \multicolumn{2}{|l}{ Sumber: Hasil Perhitungan }
\end{tabular}

Debit Saluran

Untuk mencari nilai kecepatan aliran dapat menggunakan rumus Manning yang dapat ditulis sebagai berikut:

$$
V=\frac{1}{n} x R^{2 / 3} x S^{1 / 2}
$$

Dimana:

$R=$ Jari-jari Hidraulik (m)

$S=$ Kemiringan Dasar Saluran

$n=$ Koefisien Manning

Untuk mencari debit aliran pada saluran dapat menggunakan rumus:

$$
\mathbf{Q s}=\mathbf{V} \cdot \mathbf{A}
$$

Dimana:

Qs = Debit aliran pada saluran $\left(\mathrm{m}^{3} / \mathrm{dtk}\right)$

$\mathrm{V}=$ Kecepatan Aliran (m/dtk)

$\mathrm{A}=$ Luas Penapang Basah Saluran $\left(\mathrm{m}^{2}\right)$

Dari perhitungan didapat $\mathrm{Q}_{\mathrm{s}}$ total adalah 4,531 $\mathrm{m}^{3} / \mathrm{dtk}$.

\section{Perbandingan Antara Debit Rasional dan Debit Saluran}

Tabel. 4.9 Hasil Perhitungan Pengujian Smirnov Kolmogorov

\begin{tabular}{|c|c|c|c|c|}
\hline No & $\begin{array}{c}\text { Periode } \\
\text { Ulang Tr } \\
\text { (Tahun) }\end{array}$ & $\begin{array}{c}\text { Debit } \\
\text { Rasional } \\
(\mathrm{Qr}) \\
\mathrm{m}^{3} / \mathrm{det}\end{array}$ & $\begin{array}{c}\text { Debit } \\
\text { Saluran } \\
(\mathrm{Qs}) \\
\mathrm{m}^{3} / \mathrm{det}\end{array}$ & $\begin{array}{c}\text { Hasil } \\
\text { Perbandingan }\end{array}$ \\
\hline 1 & 2 & 0.042 & 4.531 & Tidak Banjir \\
\hline 2 & 5 & 0.054 & 4.531 & Tidak Banjir \\
\hline 3 & 10 & 0.062 & 4.531 & Tidak Banjir \\
\hline 4 & 25 & 0.073 & 4.531 & Tidak Banjir \\
\hline
\end{tabular}




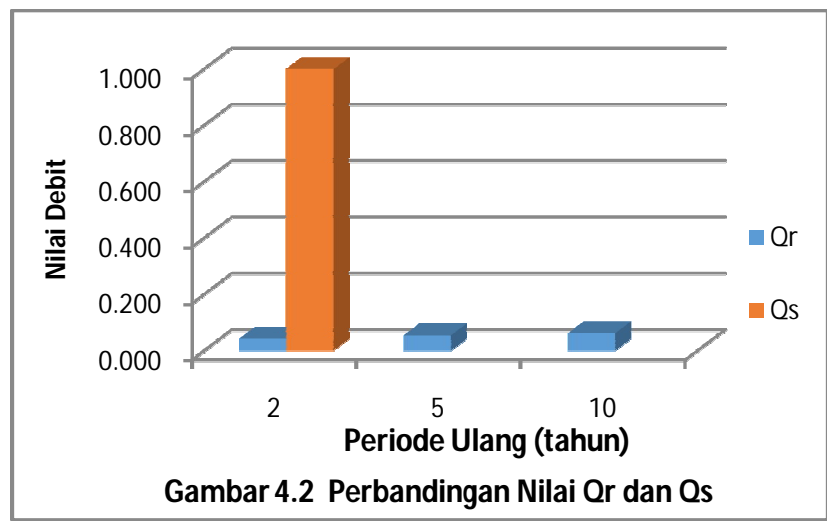

\section{KESIMPULAN}

1. Berdasarkan hasil data lapangan saluran eksisting, lebar dasar saluran (b) bervariasi antara $0,25 \mathrm{~m}-0,50 \mathrm{~m}$, dan kedalaman saluran bervariasi antara $0,35 \mathrm{~m}-0,70 \mathrm{~m}$.

2. Dari hasil perhitungan daerah kawasan garuda XA menunjukkan perbandingan bahwa Qr < Qs per periode 2, 5, 10, 25 sehingga dikatakan tidak banjir dan sudah cukup untuk kapasitas dimensi saluran.

2. Kondisi banjir yang terjadi pada waktu tahun 2015 adalah keadaan genangan sesaat dikarenakan pada lokasi tertentu dibeberapa tempat tidak mempunyai saluran.

\section{SARAN}

1. Dari hasil kajian di beberapa lokasi tidak adanya drainase dan kurang terawatnya drainase yang ada, maka diperlukan pemeliharaan agar drainase di kawasan penelitian dapat mengalirkan air dan tidak menyebabkan genangan.

2. Perlunya di desain kembali debit aliran dan arah aliran agar dapat mengalir dengan baik.

3. Agar saluran drainase dapat berfungsi sebagaimana mestinya dalam kurun waktu yang lama, maka perlu diperhatikan masalah pemeliharaan dan normalisasi saluran tersebut dari pihak masyarakat dan dari dinas atau instansi yang berkaitan
Badan Meteorologi, Klimatologi dan Geofisika (BMKG) Propinsi Kalimantan Tengah, 2015, Data Hujan wilayah Palangka Raya. Palangka Raya.

Novrianti, 2005, Kajian Drainase Terhadap Banjir Pada Kawasan Jalan Sapan Kota Palangkaraya, Media Ilmiah Teknik Sipil, Vo. 4 No. 1 Desember 2015. ISSN 0216 - 1346, ISSN 2407 - 3857 E. 2015

Pedoman Drainase Perkotaan dan Standar Desain Teknis.

Sofian, dkk. Perencanaan Teknis Drainase Kawasan Kasang Kecamatan Batang Anai Kabupaten Padang Pariaman. Jurnal Momentum. Vol. 14 no. 1 Februari 2013. ISSN: 1693-752X. 2014

Suripin. 2004. Sistem Drainase Perkotaan yang Berkelanjutan. Andi Offset. Yogyakarta.

Sutanto, 2006, Pedoman Drainase Jalan Raya. Penerbit Universitas Indonesia. Jakarta

Triatmodjo. Bambang, 2010, Hidrologi Terapan, Cetakan Kedua, Beta Offset, Yogyakarta

\section{DAFTAR PUSTAKA}

Ayu. Ida, dkk. 2013. Analisis Kapasitas Saluran Drainase Sekunder. 